\title{
FRONTEIRAS DE GÊNERO E A SEXUALIDADE NA VELHICE
}

\section{Guita Debert Mauro Brigeiro}

Uma das questões defendidas pela gerontologia ${ }^{1}$ brasileira nas últimas décadas, em clara consonância com a tendência verificada em âmbito internacional, é a de legitimar a inclusão da velhice no curso da vida sexual. O discurso dos especialistas inclui a sexualidade como um dos pilares do "envelhecimento ativo", modelo de gestão do envelhecimento mais generalizado no mundo contemporâneo. Além de argumentarem sobre a possibilidade de se praticar o sexo até o fim da vida, gerontólogos e sexólogos descrevem-no como uma atividade benéfica para o envelhecimento bem-sucedido. Depreende-se desses argumentos uma caraterização particular dos corpos, dos prazeres sexuais, da subjetividade masculina e feminina na velhice e, consequentemente, o estabelecimento de novos parâmetros para pensar os significados do que é ser velho.

Artigo recebido em 07/08/2011

Aprovado em 06/03/2012
O objetivo do presente artigo será exatamente o de descrever as características desse processo que chamaremos de "erotização da velhice", discutir alguns de seus possíveis significados no marco das formas contemporâneas de gestão do envelhecimento e analisar as diferenciações de gênero que aí se operam, bem como certas fusōes. Tomamos como base para nossa reflexão algumas publicações nacionais e internacionais sobre sexualidade na velhice, bem como dados etnográficos extraídos de pesquisas brasileiras realizadas em espaços de sociabilidade de velhos. Estes dados exemplificam o ponto de vista de mulheres participantes de grupos de terceira idade e de homens integrantes de associações de aposentados ou de redes de sociabilidade masculina a respeito do tema e servem de excelente contraponto para pensar os parâmetros estabelecidos pelos especialistas.

Além das questôes de gênero implicadas nessa produção sobre a sexualidade na velhice, o caso em 
análise põe em evidência o tema da relevância da idade no discurso gerontológico. Quando se trata de envelhecimento, diferentes saberes especializados concordam atualmente que a sexualidade não se esgota com o passar dos anos, ao contrário do sentido comum atribuído ao assunto. Apesar de advertir sobre o declínio da frequência de atividade sexual com o avanço da idade, a gerontologia e outras áreas do conhecimento afirmam que esse decréscimo é substituído por uma intensidade ampliada do prazer sexual. A argumentação dos especialistas integra, nesse sentido, duas posições aparentemente contraditórias. Ao menos no nível ideal, defendem que a sexualidade não depende da idade dos sujeitos, e ao mesmo tempo sustentam que o envelhecimento facilitaria uma experiência sexual mais gratificante. Desvincula-se simbolicamente a sexualidade da idade dos sujeitos, em seu sentido excludente, para reinseri-la nas etapas mais avançadas do curso da vida com uma ênfase positiva. Notamos que a irrelevância da idade no que se refere à experiência sexual é matizada também em função dos dispositivos estabelecidos pelos expertos na busca da erotização da velhice, uma vez que estes dependem de tecnologias geralmente centradas na idade dos sujeitos.

A questão que orientou a leitura desse material foi a de saber em que medida essas tecnologias tendiam a indicar a velhice como um momento de rompimento desse binômio indivisível - homem/ mulher - que parece definir os limites contra os quais se esbatem as mais variadas tentativas de testar a flexibilidade do corpo humano. ${ }^{2} \mathrm{O}$ que pretendemos mostrar é que o processo de erotização da velhice conduzido pelos saberes especializados reproduz simultaneamente uma normatividade heterossexual e sugere como parte das prescrições para um envelhecimento bem-sucedido uma inversão do que é tido como próprio da sexualidade feminina e masculina. Uma das vias especialmente proposta pela gerontologia e a sexologia para tal empreitada é a desgenitalização da sexualidade masculina, insistindo na importância de que os homens na velhice explorem novas áreas de prazer em seus corpos, uma sexualidade mais complexa e difusa, tal qual estas disciplinas reconhecem ser típico do universo feminino. No caso das mulheres, um dos caminhos para manutenção da atividade sexual é o questionamento dos códigos morais mais restritivos que supostamente fundamentaram seu aprendizado da sexualidade. Estimula-se, por exemplo, que elas não vinculem mais a prática sexual ao desejo do parceiro e sim ao seu próprio, e que a velhice traga consigo também a possibilidade de liberar-se da preocupação com os filhos e com o julgamento da sociedade, para assim assumir abertamente seu interesse pelo sexo. Encontramos nestes exercícios subjetivos um cruzamento dos modelos que caracterizariam o comportamento sexual masculino e feminino, desestabilizando e desafiando convenções arraigadas sobre o tema.

\section{Processo de erotização da velhice}

A velhice como um momento de declínio sexual inevitável e universal representa um esquema interpretativo básico que marcou a história da reflexão sobre o envelhecimento, bem como, de acordo com Katz e Marshall (2003), moldou a expectativa de que os indivíduos deveriam se ajustar a esse imperativo, de modo a usufruir dos benefícios morais da maturidade pós-sexual. A sabedoria do século XIX postulava que um estilo de vida prudente deveria procurar retardar esse declínio, mas aceitá-lo era parte do exercício moral de ajustamento aos efeitos do processo de envelhecimento. Ainda, como mostram esses autores, a associação entre rejuvenescimento e restauração das funções sexuais já se encontrava no passado nas propagandas de poções e terapias, vistas então como charlatanearia ou práticas de baixa reputação. Interessante notar que a hostilidade que vigorava em relação ao rejuvenescimento foi engendrada em virtude de sua associação com o sexo.

O panorama atual configura-se de modo diferente: a inclusão da velhice no curso da vida sexual é o imperativo que marca a reflexão dos especialistas sobre o tema, o que acontece em consonância com as tendências teóricas vigentes no campo gerontológico nas últimas décadas. Uma velhice sexualmente ativa vem se estabelecendo como um ideal defendido por gerontólogos e outros especialistas afins ao tema, e é intensamente propagado pelos meios de comunicação de massa. 
A gerontologia moderna enfatiza os ganhos que o envelhecimento trás, em oposição à gerontologia mais tradicional que tendia a pensar a velhice como uma situação de decadência física e perda de papéis sociais. ${ }^{3}$ É útil voltar até o final da década de 1960, quando duas grandes teorias dominavam os enfoques no interior da Gerontologia Social, a teoria da atividade e a do desengajamento. Para ambas, a velhice é definida como um momento de perda de papéis sociais, e trata-se de argumentar, nos dois casos, como se dá o ajustamento pessoal a essa situação definida como de perda e de mensurar o grau de conformidade e o nível de atividade dos idosos. Enquanto a teoria da atividade considera mais felizes os idosos que encontram atividades compensatórias, permanecendo ativos (Cavan, 1965), a outra teoria vê, no desengajamento voluntário das atividades, a chave do envelhecimento bem-sucedido (Cumming e Henry, 1961). ${ }^{4}$

Autores como Silverman (1987) consideram que o debate em torno dessas teorias não ocupa mais a cena no interior da gerontologia. No entanto, importa observar que se o debate desapareceu, isso não foi devido a uma superação de tais enfoques, e sim ao predomínio de um sobre o outro. Lawrence Cohen, (1994), neste sentido, considera impressionante o modo como a teoria da atividade e o envelhecimento ativo ganharam espaço na reflexão mais recente sobre a velhice. Como mostra Brigeiro (2002), a defesa veemente da ideia de que a sexualidade não se extingue na velhice indica, de igual modo, o triunfo da teoria da atividade e do silêncio discursivo que previa vantagens com o desengajamento.

$\mathrm{Na}$ produção recente dos especialistas, a visão do envelhecimento como uma situação de decadência física e perdas de papéis sociais é notadamente eclipsada pela ideia dos ganhos que o envelhecimento potencialmente possibilita. As etapas mais avançadas da vida são tratadas atualmente como momentos privilegiados para novas conquistas, sendo estas guiadas pela busca do prazer, da satisfação e da realização pessoal. As experiências vividas e os saberes acumulados são ganhos que propiciariam aos mais velhos oportunidades de explorar novas identidades, realizar projetos abandonados em outras etapas da vida, estabelecer relações mais profícuas com o mundo dos mais jovens e dos mais velhos. Essas novas imagens acompanham a construção da categoria "Terceira Idade", derivada também do modelo de envelhecimento ativo, que busca transformá-lo em uma experiência mais gratificante (Debert, 1999). Um conjunto de discursos empenhados em rever estereótipos negativos da velhice abre espaço para que experiências bem-sucedidas de envelhecimento possam ser vividas coletivamente. Uma nova linguagem pública empenhada em alocar o tempo dos aposentados faz-se presente na desconstrução das idades cronológicas como marcadores pertinentes de comportamentos e estilos de vida. Uma parafernália de receitas envolvendo técnicas de manutenção corporal, comidas saudáveis, medicamentos, bailes e outras formas de lazer é proposta, desestabilizando expectativas e imagens tradicionais associadas a homens e mulheres em estágios mais avançados da vida. É no marco dessas transformações que podemos localizar o processo vigente de erotização da velhice.

No que diz respeito às discriminações identificadas contra os mais velhos, considera-se que é próprio das sociedades como a nossa reprimir sua sexualidade. Tal repressão não é somente exercida pelos mais jovens, mas também efetuada por parte dos próprios velhos. A ideia de um "mito da velhice assexuada" surge nas últimas três décadas como um consenso na literatura gerontológica, o que se verifica também na abordagem do tema realizada por especialistas que se definem profissionalmente fora do campo, como alguns psicanalistas, demógrafos, entre outros. Independentemente do enfoque conceitual adotado, a maioria das publicações menciona a existência de uma concepção social do fim da vida sexual na velhice, tida como generalizada e errônea. Evidenciada através de uma série de preconceitos, a leitura convencional sobre o assunto seria responsável inclusive por uma interdição simbólica da prática sexual nos momentos mais avançados da vida. Cabe ressaltar que o termo "assexuada" é empregado pelos próprios especialistas, geralmente com sentido adjetivo, denotando ausência, anulação. ${ }^{5}$

É contra esta problemática que se enumeram os diversos argumentos dos especialistas, buscando demonstrar que o curso da vida sexual não se extingue ao longo dos anos. Seja através de uma 
forte referência às mudanças na fisiologia da atividade sexual, seja mencionando as complexas dinâmicas do funcionamento psíquico, seja ainda por uma alusão às dinâmicas conjugais ou às variações de frequência e de tipologia das práticas sexuais, os autores são unânimes em afirmar que a associação excludente entre idade e sexualidade é uma representação equivocada. As modificações na expressão da sexualidade associadas ao processo de envelhecimento são descritas de forma abundantes nesta literatura, porém o intuito é o de demonstrar que, apesar de diminuírem, o interesse e a atividade sexual permanecem por toda a vida, refutando, assim, a ideia de uma "assexualidade" na velhice, no sentido de falta de interesse ou de prática sexual. Vejamos o seguinte fragmento extraído de um artigo sobre o tema:

[...] a sociedade acredita que tanto o homem quanto a mulher que atingem uma idade avançada perdem totalmente a capacidade, o interesse e o desejo de manter uma atividade sexual pelas modificações fisiológicas que ocorrem no processo de envelhecimento. Esta visão, porém, não é correta e este ciclo [da resposta sexual humana], mesmo possuindo alterações, se faz representar na vida de um indivíduo mais velho (Risman, 1995 , p. 54$).^{6}$

Esse tipo de enunciado vem, na maioria das vezes, acompanhado de uma reflexão sobre o caráter da sexualidade na velhice. A despeito da diminuição de sua frequência, reconhecida empiricamente, o empenho das argumentaçóes é o de mostrar que a sexualidade é algo muito mais amplo do que o ato de copular. Se por um lado, de acordo com esta literatura, a sexualidade tem pouco ou nada a ver com a idade, por outro a velhice exige uma nova forma de experimentá-la. Verifica-se aqui o emprego de uma retórica que visa redefinir a sexualidade segundo parâmetros mais acessíveis às pessoas na velhice.

A sociedade taxa os velhos de "menos homens e mulheres", de "seres assexuados". É um grande malefício que se faz com indivíduos de idade avançada, porque muitos são os que podem até usufruir mais do que quando eram jovens. A sexualidade tem pouco ou nada a ver unicamente com ereçôes e orgasmos, e sim com comunhão, com tocar e se deixar tocar, acariciar e ser acariciada, ter e dar prazer. É só conseguir mudar o padrão de encarar e de atuar, usando formas abertas e receptivas entre si, que se chega ao nirvana nos encontros amorosos (Fucs, 1992, p. 94).

Uma das chaves para compreender o que descrevemos aqui é a confluência verificada em boa parte desta literatura entre a gerontologia e a sexologia. Pressupostos e conceitos de um e outro campo são tomados de empréstimo como referência fundamental, fazendo-se valer de certo prestígio que gozam no tratamento dos problemas do envelhecimento e da sexualidade, respectivamente. A sexologia, por definir-se preponderantemente como uma disciplina de caráter aplicado, oferece os recursos necessários à gerontologia em sua empreitada de intervenção sobre o sexual. A relação no sentido inverso é igualmente válida, ou seja, do emprego de preceitos do envelhecimento ativo na argumentação sexológica.

Cabem ainda alguns esclarecimentos sobre a delimitação e a definição do campo sexológico e dos nexos que guarda com a gerontologia. Os parâmetros que orientam o saber-fazer da sexologia abarcam descriçôes sobre a fisiologia implicada no ato sexual, as variações de expressão da sexualidade, incluídas as relacionadas com o curso da vida, e determinadas premissas sobre os significados sociais e subjetivos da sexualidade. Como afirma Brigeiro, com precisão, a sexologia é

[...] uma disciplina de cunho prático, adota como estratégia terapêutica um conjunto de prescrições, que vão desde o uso de medicamentos e outros recursos de intervenção física, até técnicas pedagógicas de modelação do comportamento e dos usos dos corpos, com vistas a promover um melhor funcionamento da vida sexual. No caso dos idosos a meta, na maior parte das vezes, é a de "maximizar" ou "otimizar" o exercício sexual desses (2002, pp. 10-11). 
$\mathrm{Na}$ caracterização da sexologia realizada no Brasil, Russo et al. (2011) mostram que esse é um campo profissional e de produção de conhecimentos com fins de atenção clínica ou prevenção de problemas sexuais. Embora o termo "sexologia" seja bastante usual, nem sempre é empregado pelos próprios atores que integram este campo. Utilizando o termo sexologia mais no sentido metodológico e menos como uma expressão êmica, a pesquisa aponta para as diferenciações acionadas no uso social desta e de outras designações classificatórias neste universo científico e profissional. De acordo com os autores, o campo define-se atualmente no país por duas vertentes, a educação sexual e a clínica sexual, sendo esta última conformada por duas outras vertentes que convivem com certo grau de tensão: a medicina sexual e a sexologia clínica. A respeito destas últimas, a primeira adota uma perspectiva estritamente biomédica e fisicalista e é representada, sobretudo, por urologistas. A segunda, por sua vez, reproduz uma visão mais holista da sexualidade e reúne em torno de si uma gama profissional multidisciplinar. $\mathrm{Na}$ sexologia clínica também vigora uma visão naturalizada ou essencializada da sexualidade, ainda que a abordagem fisicalista prime destacadamente no campo da medicina sexual.

A distinção descrita por Russo et al. é especialmente interessante para a análise sobre os nexos da gerontologia com o campo de saberes sobre a sexualidade. Não obstante as preocupações e as produções da medicina sexual integrarem o processo contemporâneo de erotização da velhice que descrevemos aqui, este é o ramo científico-profissional com que a gerontologia social estabelece menor interlocução. Sem dúvida, esse diálogo parece mais profícuo com a sexologia clínica. Talvez a formação multidisciplinar desta e da gerontologia bem como a tentativa de ambas por integrar visóes que considerem aspectos biológicos, mas não se reduzam a eles, sejam as principais razôes para a afinidade entre estes campos e o relativo distanciamento em relação à medicina sexual. A mútua referência de conceitos e pressupostos entre a gerontologia e a sexologia clínica respalda, por um lado, a inclusão da dimensão sexual no modelo de envelhecimento ativo e, por outro, estende também para os velhos a máxima sexológica do prazer sexual como um direito humano, consequentemente universal, e parte indissociável do bem-estar físico e subjetivo.

$\mathrm{Na}$ trama dessas confluências opera-se uma redefinição do que se entende por sexualidade, e de sua resultante emergem vários aspectos interessantes sobre os atributos de gênero e o que se supóe ser a gramática masculina e feminina dos comportamentos sexuais. O que mais se destaca na produção escrita sobre o tema é seu viés heteronormativo. Toda a descrição da fisiologia sexual, das dinâmicas de conjugalidade no curso da vida, e as argumentaçôes sobre as formas de experimentar a sexualidade são condizentes com a gramática heterossexual. A ausência de menção à homossexualidade é notória, sendo inclusive sublinhada em alguns textos (Ludeman, 1981; Ferigno, 1988). Vale reiterar que especialistas diferentes dos gerontólogos e sexólogos compartem esta mesma abordagem no tratamento do tema. Também na produção de psicanalistas, demógrafos e sanitaristas sobre a velhice, a modalidade sexual a ser resgatada, estimulada e glorificada é a heterossexual. Nesse sentido, a literatura sobre o tema está fortemente afiliada à tendência verificada nas últimas décadas de englobamento das sexualidades ditas normais - heterossexual e vivida no âmbito conjugal - no universo de intervenção dos especialistas, como bem indicou Bejín (1987) e é claramente demonstrada por outros estudiosos (Russo et al., 2011). ${ }^{7}$

A velhice parece instaurar uma nova etapa do curso da vida sexual, o que se pode verificar não somente na reiteração discursiva do prolongamento da sexualidade no curso da vida, como também na descrição dos problemas sexuais enfrentados por homens e mulheres na velhice e nas tecnologias específicas formuladas como parte de sua solução. Os conselhos referentes à terapia e à educação sexual, por exemplo, sugerem um deslocamento da sexualidade da área genital para diversas "zonas erógenas" do corpo. A ampliação é de tal ordem que não há parte da superfície do corpo dos velhos que não seja potencialmente fonte de prazer, ultrapassando a própria noção de "zona", uma vez que do ponto de vista dos especialistas não há limites e demarcações nesse sentido. As citaçôes apresentadas a seguir ilustram bem este deslocamento. 
As expressões de afeto, as fantasias, o desejo de ser seduzido e seduzir, estão presentes na vida dos velhos como em qualquer outra etapa da vida, embora nem sempre se apresente da mesma forma. Resgatar o direito a uma vida sexual do velho implica poder pensar o amor em suas formas de transformação libidinal, ou seja, outras formas de amor, que passam pela ternura, pelos contatos físicos que erogenizam o corpo, como o olhar, o toque, a voz, redescobrindo as primeiras formas de amor do ser humano. [...] $\mathrm{O}$ velho não deixa de amar, mas reinventa formas amorosas (Santos, 2003, pp. 22-23).

[...] com o envelhecimento, quando as funções orgânicas sofrem em seu desempenho uma perda sexual, decorrente das mudanças hormonais ou de alguma doença incapacitante, a libido, ou seja, a energia sexual, que privilegia o aparelho genital para a sua realização, retorna seu investimento a outra áreas do corpo marcadas nas primeiras experiências, retornando ao prazer encontrado em outras formas erógenas, como o toque, o olhar, a delicadeza de toda sensibilidade. A sexualidade, como manifestação de amor, de afeto, toma outras formas de expressão. [...] São os preconceitos que fazem pensar que a chamada andropausa no homem e a menopausa na mulher são responsáveis pelas dificuldades sexuais. A perda de hormônios modifica o mecanismo e a frequência da ereção, assim como altera a lubrificação vaginal, dificultando a realização do coito. Isso parece decretar que a penetração é a única fonte produtora do prazer e que a ausência ou as dificuldades dessas possibilidades funcionais incapacitam o velho como ser sexuado [...] o que interfere na vida sexual do velho é de ordem psicológica e social (Idem, pp. 29-30).

$\mathrm{Na}$ literatura analisada, essa ampliação das zonas erógenas ou de prazer aparece sob a forma de relatos dos próprios velhos, mas é, sobretudo, como conselhos ou prescrição dos especialistas que ela se destaca. Conforme ressaltado na citação a seguir, a desgenitalização aparece especialmente associada aos homens.
[Homens e mulheres mais velhos] Relatam uma vivência diferente de seu corpo, do corpo do(a) parceiro(a) e da própria relação. Não mais a premência da descarga do orgasmo, não mais, principalmente entre os homens, as sensaçôes eróticas concentradas apenas nos genitais, mas sim a erotização plena de toda a epiderme, sexo de corpo inteiro e de espírito inteiro. Sexo sem pressa. Não mais o "hambúrguer com batatas fritas" devorado sofregadamente na juventude, mas sim um prato cuidadosamente elaborado e delicadamente saboreado (Ferrigno, 1988, p. 16).

Para os especialistas, os homens seriam geralmente mais limitados em sua concepção de sexualidade, comparativamente às mulheres, tendendo a concentrar seus interesses na região genital e no recurso à penetraçãa. A prescrição de redescoberta de outras partes "sexualizadas" do corpo na velhice recai assim principalmente sobre eles, deixando subentendido as alteraçóes identificadas na capacidade de ereção com o avançar da idade. Os homens também são descritos como mais interessados por sexo e possuindo uma frequência maior de relações sexuais em comparação com as mulheres. As conclusões sobre o universo feminino são as de que elas apresentam menores dificuldades quanto à vida sexual na velhice, já que a sexualidade delas, segundo indicam, sempre foi mais complexa e 'menos localizada'. Quando um desinteresse por relaçôes sexuais é por elas afirmado, o trabalho de intervenção envolve a indicação de uma reeducação sexual no sentido da "liberação da repressão". De acordo com os estudos e os ensaios, a atividade sexual feminina depende muito da intenção masculina. A diminuição da atividade sexual das mulheres na velhice é associada ao surgimento de doenças dos seus cônjuges, ao desinteresse destes e também à sobremortalidade masculina. Os dados sustentam que elas, além de se mostrarem menos interessadas por sexo, tiveram uma socialização marcada por maior controle, o que lhes dificultaria desfrutar a sexualidade na velhice. E é sobre tais aspectos que se deve trabalhar, supostamente para que elas tenham uma "vida sexual plena”. A velhice seria um momento propício para essa libertação, na medida em que as experi- 
ências acumuladas e o desprendimento das funçōes reprodutivas, de cuidado dos filhos pequenos e de uma família muitas vezes extensa permitem um distanciamento do conjunto de convenções relacionadas com o mundo feminino.

É parte dos estudos sobre a sexualidade, como mostra Luiz Fernando Dias Duarte (2004), ${ }^{8}$ a dificuldade envolvida na tensão entre, por um lado, "uma incitação a falar sobre o sexo" (Foucault) e, por outro, um movimento que retrai essa fala ou mesmo a reflexão sobre o tema, dada a correlação entre sexualidade, intimidade e privacidade. Essa tensão acaba por levar a uma separação entre dois níveis da experiência: o sensual e o sentimental. Um prazer sensorial do sexo (dito sensual) e um prazer afetivo sentimental (correspondente em nossa cultura à ideologia do amor). É próprio destes estudos estabelecer uma correlação entre o sensual e o masculino e entre o afetivo e o feminino. Essa correlação é que tende a ser revista quando se pensa em sexualidade e velhice.

A inversão dos atributos de gênero que ocorreria na velhice é tratada nos seguintes termos pelo psicanalista Kernberg:

Pode-se observar um desenvolvimento curioso da relação entre o desejo erótico e o amor apaixonado ao se estudar as relaçôes amorosas que se dão mais tarde na vida. [...] o desenvolvimento masculino e feminino da integração entre excitação sexual e ternura diferem. [...] Para os homens, [...], a liberdade sexual precede a capacidade de estabelecer uma relação de objeto profundo com uma mulher, e de integrar liberdade sexual no contexto desse relacionamento amoroso.

No caso das mulheres, ao contrário [...]. A patologia mais frequente, nesse sentido, é um certo grau de inibição sexual no contexto do estabelecimento de um relação amorosa satisfatória. [...] vindos de caminhos de desenvolvimento contrastantes, homens e mulheres alcançam a mesma capacidade de síntese entre liberação sexual e uma relação de objeto profunda; na realidade, o amor apaixonado é precisamente o selo dessa síntese entre o desejo erótico e o amor terno. Agora, sob a luz da observação das relaçōes amorosas de casais mais velhos, sugiro que esse desenvolvimento prossegue na idade mais avançada, com uma surpreendente reversão de papéis. Homens apaixonando-se e estabelecendo uma relação amorosa apaixonada nas etapas mais avançadas de suas vidas frequentemente têm uma estimulante experiência de que seu intenso amor sexual por uma mulher transcende, em novas formas, seu desejo erótico [...]. Ao contrário, as mulheres que se apaixonam nas etapas mais avançadas de suas vidas podem experimentar uma liberdade de desejo sexual que torna o amor pelo homem que encontraram agora uma ponte na qual o desejo erótico pode ser plenamente satisfeito, e torna-se a maior expressão do amor deles (2001, pp. 183-184).

A batalha empreendida pela gerontologia contra a ideia de que velhice e sexualidade não são mutuamente excludentes não é tarefa fácil. Trata-se de uma disputa contra o senso comum, para o qual, como mostra Simóes:

O declínio do desejo, a perda da atratividade física e o virtual apagamento como pessoa sexuada estão entre as principais marcas e condições do envelhecimento que sustentam, em grande parte, o repúdio e o medo generalizado do corpo em degradação e, em contrapartida, a avaliação positiva que se faz da juventude (2004, p. 417).

O esforço desses especialistas por ampliar as potencialidades da sexualidade humana, desgenitalizando os corpos ou invertendo as convençōes sobre a sexualidade feminina e masculina, resulta também em uma batalha contra a indústria farmacêutica, empenhada em reduzir a sexualidade aos termos de disfunçôes sexuais tratáveis e acentuar a penetração como cerne das preocupações masculinas e do casal. A crítica advinda do campo gerontológico a este tipo de perspectiva não é direta, mas a ideologia sustentada cria uma tensão com a lógica das disfunções sexuais.

Vários autores têm destacado que o lançamento do Viagra representa um marco paradigmático nas 
formas de pensar sobre sexo (Bajos e Bozon, 1999; Giami, 1998; Bozon, 2004; Brigeiro e Maksud, 2009). No caso brasileiro, assim com em outros países, o lançamento do Viagra envolveu um intenso trabalho de publicidade e de promoção por parte dos meios de comunicação. Como bem mostram Brigeiro e Maksud (2009), as estratégias discursivas de divulgação deste medicamento em nosso país estiveram fundamentadas sobre um claro apelo a convenções assimétricas e tradicionais de gênero, o que poderia ser pensado como um paradoxo ante um cenário contemporâneo permeado por questionamentos acerca das desigualdades nas relações entre os sexos e entre diferentes expressões da sexualidade. As imagens que ajudaram a construir o Viagra no universo simbólico brasileiro se reduzem a do casal heterossexual, no qual o homem é valorizado, sobretudo, por sua potência sexual e por assumir o protagonismo no encontro erótico com a parceira. A mulher, por sua vez, é apresentada em uma posição subordinada, passiva e complacente aos avatares do desejo masculino. Os discursos sobre o Viagra interessam aqui especialmente por sua intensificação do valor dos genitais e da penetração na relação sexual. É certo que o surgimento do Viagra aporta ao processo de erotização da velhice discutido neste artigo, no entanto o faz na contramão das prescrições defendidas pelos especialistas em envelhecimento. A lógica ao redor da medicalização da impotência masculina prescinde de qualquer necessidade de revisão de conceitos sobre as formas de experimentação do prazer, como a de estímulo ao descobrimento de novas zonas erógenas.

Essa é também uma batalha contra uma parcela significativa do segmento mais velho da população, como veremos a seguir.

\section{As obrigações do sexo}

Uma das características definidoras dos trabalhos de cunho etnográfico sobre a experiência do envelhecimento é a tentativa de questionar a importância e a universalidade das imagens sobre a velhice que marcaram os pressupostos fundadores $\mathrm{da}$ gerontologia. Para as primeiras geraçôes de gerontólogos, pensar o envelhecimento nas sociedades industrializadas era opor uma Idade de Ouro, na qual os velhos eram membros valorizados e ativos de uma família extensa, à situação atual, em que as mudanças trazidas pelo processo de modernização/industrialização acabaram por relegá-los a uma existência sem significados, a um papel menor, tanto na família como na sociedade. Essa perspectiva marca o discurso gerontológico brasileiro até os anos de 1970 em seu empenho em sensibilizar o poder público e a sociedade para a importância de estudos e de ações voltadas para um envelhecimento populacional bem-sucedido.

As pesquisas de cunho etnográfico desenvolvidas no país a partir desta data foram, no entanto, ativas na demonstração de que os especialistas no tema tendiam a superestimar a realidade problemática dos mais velhos. Os mais velhos pesquisados projetavam uma imagem muito mais positiva da sua situação do que aquela que servia de pressuposto à teoria gerontológica, revelando não apenas que o conhecimento sobre essa realidade era muito vago e carregado de pessimismo, mas também que a gerontologia alimentava uma série de mitos relacionados com essas imagens negativas.

Tornstam (1992), na análise que faz desse mesmo movimento na Suécia, mostra, ainda, que as imagens pessimistas da velhice têm muita vitalidade, permanecendo de maneira engenhosa como fundamento teórico, mesmo quando os dados exigem uma revisão da perspectiva da miséria. Assim, por exemplo, quando as pesquisas revelam um bom nível de integração social e contatos frequentes dos idosos com seus filhos, conclui-se que os processos de urbanização e de industrialização têm efeitos negativos imediatos, mas que só se fazem sentir depois de algumas geraçóes. Salva-se a teoria com o argumento de que os efeitos que ela pressupõe não tiveram tempo de se tornar aparentes. $\mathrm{O}$ mesmo ocorre no tratamento da aposentadoria. O pressuposto é de que o abandono do trabalho leva a uma situação traumática que envolve a perda da autoidentidade e do equilíbrio psicológico. Esse é um pressuposto tão fortemente sedimentado na gerontologia que, quando os dados contradizem os efeitos negativos esperados da aposentadoria, a tendência é apontar para erros na metodologia empregada na pesquisa antes de discutir se a teoria é ou não correta. 
Algo muito semelhante ocorre em relação à sexualidade. Para os estudiosos, é impossível atualmente imaginar qualidade de vida sem a dimensão sexual plenamente realizada. Esta visão é incompatível com dados etnográficos sobre mulheres mais velhas que afirmam estarem vivendo a melhor etapa de suas vidas, porque, entre outras coisas, a velhice permitiu que elas se liberassem de mais essa obrigação. A tendência dos analistas é considerar que as amarras à moralidade vigente explicam esse tipo de declaração.

Verificamos que na base da abordagem dada à questão da sexualidade dos velhos também persiste a imagem de uma velhice discriminada, reprimida, usurpada de direitos, panorama que requer atenção dos especialistas e demanda açôes específicas para sua redenção. Alguns registros etnográficos e de pesquisa sociológica sobre a experiência da velhice no Brasil, ainda quando não tratam diretamente sobre a sexualidade, ajudam a lançar luz sobre as tecnologias de intervenção sobre a velhice. Trata-se de estudos cujos dados permitem refletir sobre as lógicas de gênero que permeiam tais intervenções.

Um dos focos desses estudos têm sido os programas para a "terceira idade". No Brasil, esta categoria se popularizou recentemente e com muita rapidez e é uma forma de tratamento das pessoas de mais idade que ainda não adquiriu uma conotação depreciativa. Tais programas, criados nos anos de 1960, com iniciativas pioneiras, sobretudo do Serviço Social do Comércio (Sesc), proliferam nos anos de 1990 e marcam presença mesmo em municípios em que a população idosa é relativamente pequena. Aberto para pessoas com 50 anos ou mais, as pesquisas têm mostrado que neles o público mobilizado é, sobretudo, feminino. A participação masculina raramente ultrapassa os $10 \%$ e o entusiasmo manifestado pelas mulheres na realização das atividades propostas contrasta com a atitude de reserva e indiferença dos homens que, em número muito diminuto, raramente perdem uma oportunidade de olhar com desconfiança o entusiasmo das mulheres.

Apesar da diversidade de atividades desenvolvidas em cada um destes programas - como são os centros de convivência de idosos, as "universidades para a terceira idade", os grupos da "melhor ida- de" -, das diferenças em termos de recursos disponíveis e das diferenças socioeconômicas do público feminino mobilizado, o tom geral é o de rever os estereótipos com que a velhice é tratada. Inspirados nas recomendações do Plano de Ação Mundial para a Velhice, tais programas reiteram a ideia de que o velho é um ser integrado que necessita de uma assistência especializada e que deve reencontrar seu lugar na sociedade, recuperando sua autoestima. Centrar a análise nesses programas é se perguntar o que acontece com os homens mais velhos. Será que eles não participam de atividades associativas? Olhar para as associações de aposentados ou mesmo para determinados espaços urbanos permite colocar em outros termos essa questão, porque aí se verifica a presença de grupos ou redes em que os homens ganham destaque.

O movimento dos aposentados, organizado por intermédio de associações, federaçóes e confederação, em diferentes momentos ocupou o centro da cena política brasileira nas últimas décadas: primeiro no final de 1991 e início de 1992, galvanizando a opinião pública no que ficou conhecido como "a luta pelos 147\%"; depois nos anos 2000, em manifestações contra declarações do presidente FHC que foram consideradas ofensivas aos aposentados. O trabalho de Júlio Assis Simões "Entre o lobby e as ruas: movimento de aposentados e politização da aposentadoria" (1998; ver também 2004a) traz um retrato muito interessante dessas associaçôes e dos movimentos das quais participaram. Aqui é importante chamar a atenção para o fato de que esse movimento mobilizou basicamente um público masculino. É difícil ter dados sobre a participação de mulheres no movimento, mas elas raramente têm cargo de direção nas associaçōes ou são chamadas para falar em nome dos aposentados nas manifestaçōes e na imprensa. Nos discursos políticos proferidos pelas lideranças é praxe que as interpelaçōes sejam feitas em termos de "os" aposentados e "as" pensionistas. ${ }^{10}$

A comparação entre essas duas formas associativas - a dos grupos de convivência de terceira idade e a das associaçóes dos aposentados e pensionistas - permite mostrar o caráter distinto das experiências coletivas nelas vividas. Nos dois casos está envolvida uma luta contra os preconceitos e os 
estereótipos por meio dos quais se supõe que a velhice seja tratada no contexto brasileiro. São, entretanto, formas distintas de empreender essa luta. $\mathrm{O}$ movimento dos aposentados pretende estabelecer uma aliança com outros setores desprivilegiados da sociedade, na luta contra o Estado pela redistribuição da renda e direitos civis. Nos programas para a "terceira idade", a luta é por mudanças culturais, uma luta contra os preconceitos e estereótipos, que leva a uma celebração da terceira idade e do processo de envelhecimento como momento privilegiado na vida, em que a realização pessoal, a satisfação e o prazer encontram o seu auge e são vividos de maneira mais madura e profícua.

As diferenças nas formas como homens e mulheres nas associações e nos programas representam o que é a velhice e percebem as mudanças ocorridas no envelhecimento são elementos fundamentais para entender as diferenças no público mobilizado por cada uma dessas manifestaçōes. As mulheres entrevistadas por Debert (1999) em programas para a "terceira idade", por exemplo, mostravam-se entusiasmadas com as mudanças em relação à situação da mulher, segundo consideravam acontecer na sociedade brasileira, particularmente no que diz respeito às mulheres mais velhas. Diferentemente de suas mães e suas avós, elas já não tinham que se vestir de preto e ficar em casa à espera da visita de filhos e netos. Gozavam atualmente de uma liberdade inusitada para as velhas de antigamente e também para as mulheres mais jovens. A participação nas atividades dos programas para a "terceira idade" era uma oportunidade de se envolver em atividades motivadoras, ampliar seu grupo de amigos e seu repertório de conhecimentos, explorar novas identidades e novos estilos de vida. Questôes relativas à vida sexual constituíam um tema difícil de ser abordado, embora o sexo entre velhos ou entre velhos e jovens fosse um tema privilegiado das piadas que produziam entre elas enormes gargalhadas. Expressões como "Deus que me livre, arrumar um namorado agora que já estou com 65 anos" provocavam um acordo ativo e entusiasmado entre elas, como se o avanço da idade tivesse propiciado sua libertação de mais essa tarefa. Entre as mulheres casadas, sexo e amor estão indissoluvelmente ligados e suas falas estão em sintonia com as conferências proferidas no programa e com as palestras ministradas pelas coordenadoras do grupo sobre as vantagens da sexualidade na velhice: "acho muito melhor agora sem aqueles arroubos, menos quantidade e mais qualidade"; "o amor verdadeiro entre duas pessoas da nossa idade é muito mais lindo, é fantástico..." ou "nessa idade não tem preocupação, é bem melhor, é mais tranquilo". Esse tipo de consideração - bastante afim com o discurso gerontológico - é, entretanto, prontamente rebatido pelas solteiras, separadas ou viúvas. Estas, de maneira mais ou menos discreta, desdenham as mulheres acompanhadas dos velhos e muitas vezes frágeis maridos, demonstrando uma mescla de dúvida e ironia em relação às vantagens e qualidades superiores da sexualidade na velhice apregoadas nos programas para a "terceira idade". Para esse segundo grupo de mulheres, o cuidado com a aparência é fundamental, porém a preocupação com a beleza é de outra ordem e possui um limite dado pela idade: "Agora eu estou só para meus filhos e netos [...] quero estar bonita, mas a gente sabe que o corpo não é mais o mesmo. Então como é que fica?", pergunta uma das mulheres após as conferências sobre o tema, descendo mãos e braços em frente ao peito como se quisesse mostrar que essas partes do corpo inevitavelmente caem.

Voltemos às associações de aposentados. Nelas, combater os preconceitos em relação à velhice era mostrar que seus participantes mantinham a lucidez e sabiam criticar os governos, os políticos e as interpretaçôes errôneas que a mídia fazia de todos os diferentes aspectos da vida social brasileira. Muitos deles eram críticos aos programas para a "terceira idade", que alguns chamavam de "playground de velhos", que desviavam aposentados e pensionistas de seus reais interesses. Outros - principalmente os que tinham interesse de fazer uma carreira política - eram mais respeitosos em relação a esses programas, e propunham planos de juntar atividades como passeios, bailes e outras atividades físicas ao trabalho das associações.

$\mathrm{Na}$ pesquisa realizada em bailes da cidade do Rio de Janeiro em que mulheres de 60 anos ou mais contratam homens jovens e de origem mais modesta para acompanhá-las, exercendo as funçōes de companheiros, Andréa Moraes Alves mostra que 
a erotização dos corpos por elas empreendida não implica na busca de relações sexuais. Como disse uma de suas informantes "mulher nova não aguenta ficar sozinha. Eu só estou aguentando depois dos 65 anos, quando meus hormônios me deixaram em paz" (2004, p. 107) A autora mostra que mulheres por ela pesquisadas investem no corpo aplicando um conjunto de técnicas que vão desde a compra de vestidos, maquiagem, acessórios para o baile, passando pelas dietas e exercícios físicos até cirurgias e tratamentos cosméticos. Contudo, encontrar um namorado não é visto por elas como uma motivação para participar dos bailes: "o que primordialmente se espera da relação com os cavalheiros de aluguel é que eles ajam como cavalheiro no salão: corteses, gentis e bons dançarinos. Não se espera deles, ao menos não explicitamente, que sejam namorados em potencial" (Idem, p. 142). O investimento das mulheres no corpo é também realçado no trabalho de Peixoto (2000), que oferece uma etnografia do jogo de vôlei na praia e do baile em uma das praças do Rio de Janeiro. A flexibilidade e a agilidade corporal conquistada e demonstrada nessas atividades envolvem resistência às imagens negativas do corpo envelhecido, muito mais do que um encontro sexual ou a busca de um namorado e companheiro.

$\mathrm{Na}$ pesquisa feita com mulheres de classes populares que frequentavam um programa para idosos promovido pela LBA, Motta, com muita sensibilidade, mostra o jogo de sedução que marca a experiência dessas mulheres que ela denomina de "faceiras". Considera que entre elas

[...] a sensualidade está presente não só onde há jogo amoroso, mas também numa espécie de competição entre as mulheres. Elas não se arrumam, dançam e se fazem bonitas só para os homens. A própria relação entre as mulheres serve para a afirmação de uma identidade feminina e sexuada. Mesmo quando dançam umas com as outras (quase inevitável, porque os homens são pouquíssimos), a sensualidade está presente, pois a performance acionada é toda ela sexuada e é isso que é prestigioso, não apenas aos olhos dos homens, mas das próprias mulheres (1998, p. 91).
A noção de sexo como uma obrigação que marcou as etapas mais jovens da vida está também presente nos discursos das faceiras:

Ao abordarem assuntos relativos às práticas sexuais, elas afirmam-se como seres sexuados. Não se consideram "mortas" para os assuntos sexuais e nem parecem querer que os outros as considerem assim. [...] Elas negam ter, no momento atual, intenções casadouras ou mesmo namoradeiras. Ressaltam, nesse sentido, "o trabalho que um homem dá" - do qual elas estão enfim libertas pela viuvez ou separação, enfatizando o compromisso com horários de refeiçôes (ter que "dar a janta" é tido como um jugo terrível) e o fato de terem mais roupa para lavar (Idem, pp. 101-102).

Mesmo nos asilos, como mostra Debert (1999), não estavam ausentes namoros e projetos de casamento entre os idosos. Mas, de uma maneira geral, as etnografias realizadas sobre o tema, especialmente quando realçam o ponto de vista das mulheres viúvas ou solteiras, estão em sintonia com a conclusão de Alves quando destaca que as mulheres dizem que os homens só se interessam por mulheres mais velhas "quando querem sossegar em casa e precisam de alguém para fazer o serviço doméstico" (2004, pp. 141-142).

A relação entre velhice e sexualidade é, no entanto, um tema ainda pouco estudado no Brasil. A dissertação de Brigeiro, Rir ou chorar? Envelhecimento, sexualidade e sociabilidade $(2000)^{11}$ é uma contribuição neste sentido. $\mathrm{O}$ autor realizou estudo etnográfico de uma rede de sociabilidade composta exclusivamente por homens idosos, que se reuniam numa praça e num shopping center localizados em um bairro nobre da zona norte do Rio de Janeiro. Ocupar diariamente esses espaços é garantir formas de sociabilidade fora do espaço doméstico, mas, sobretudo, resistir a mudanças impostas pelo envelhecimento e pela aposentadoria. Nas palavras de Brigeiro:

[...] apoiados numa visão do mundo em que as delimitaçôes de gênero são nitidamente demarcadas, procuram manter uma rotina 
voltada às atividades fora do espaço doméstico. A velhice, segundo suas representaçôes, se caracteriza por tentativas de resistência a qualquer mudança no estilo de vida prévio. Mais do que evidenciar um novo modelo para uma etapa da vida, os encontros diários desses senhores indicam um especial interesse por preservar certos atributos de gênero e uma organização da vida característicos de períodos passados (2000, p. 92).

Uma das peculiaridades mais acentuadas na etnografia sobre esta rede, assim como no trabalho de Motta com as "faceiras", era a jocosidade marcante em relação aos temas do envelhecimento e da sexualidade. Brigeiro mostra que as representaçōes de gênero evidenciadas nas falas entre esses homens e deles com o pesquisador expressavam a visão assimétrica que ordena as relaçôes masculino/feminino. Em diversas situações, os informantes consideram as mulheres objetos figurativos de suas proezas masculinas. Porém, as demonstrações exageradas de superioridade em relação às mulheres não refletiam uma realidade absoluta. Eram antes performances desses homens na dinâmica da sociabilidade. Sua postura chauvinista tinha como contrapeso sua adaptação às exigências conjugais, como respeitar o horário do almoço com as esposas e não dormir fora de casa.

As performances exibidas denotam que as práticas relacionadas com a sexualidade são centrais entre eles e se mantêm ao longo de suas vidas. A despeito das limitaçôes que o envelhecimento físico impõe ao exercício sexual, eles tentam demonstrar - por meio seja da jocosidade, seja dos comentários e da simulação das práticas sexuais - a importância da virilidade na interação com os outros membros do grupo. "Entre os senhores estudados parece se exercer um modelo de masculinidade hiperviril. O reconhecimento de que muitas vezes se afastam desse modelo não os impede de tomá-lo como referência, ainda que isto denote uma tensão [...]" (Idem, p. 93).

A valorização da expertise sexual e do seu desempenho é apoiada também, mas não exclusivamente, na expectativa de coito, dependente da capacidade erétil. No entanto, suas práticas e dis- cursos não parecem influenciados pelos ditames dos especialistas sobre a sexualidade na velhice.

Atestam que o desempenho sexual atual é distinto ao de épocas anteriores de suas trajetórias. De todo modo, expressam, através das performances jocosas e das práticas sexuais, a importância e a possibilidade da sexualidade em suas vidas, desvinculada, entretanto, da ideia de um novo projeto. A importância da sexualidade está associada à tentativa de continuidade de interesses e valores de masculinidade e a um movimento mais geral de resistência contra a velhice incapacitadora (Idem, p. 94).

As reflexões e as descrições documentadas pelas etnografias mencionadas indicam que a obrigatoriedade do sexo e sua relevância na velhice constituem exigências organizadas sensivelmente segundo lógicas de gênero e, do modo como se expressam nos diferentes contextos estudados, servem como importante contraponto à problematização gerontológica sobre o tema. Ainda sobre tais obrigações, cabe uma referência ao acurado balanço realizado por Simões (2004) dos estudos a respeito da homossexualidade masculina e o curso da vida. Baseado em uma revisão bibliográfica de trabalhos norte-americanos e britânicos desenvolvidos no campo das ciências humanas, o autor observa que se a valorização da juventude e a antipatia pela velhice são traços recorrentes entre os modos de pensar o envelhecimento no Ocidente, especialmente no marco da cultura de consumo atual, este par de oposição estaria bem acentuado na "cultura gay masculina" dos contextos urbanos. Em suas palavras:

Nesse cenário, aparentemente marcado pelo hedonismo complacente e pela obsessão com atributos físicos capazes de suscitar atração e desejo, em que tudo parece girar em torno de um mercado sexual hierarquizado por critérios de juventude e beleza, não haveria lugar para as pessoas de mais idade, que carregariam os estereótipos derivados da depreciação de sua atratividade como parceiros sexuais desejáveis e da decorrente marginalização pelos mais jovens (Idem, p. 418). ${ }^{12}$ 
As informações etnográficas apresentadas evidenciam as dificuldades da gerontologia não apenas de empreender uma batalha contra a indústria farmacêutica e a medicina sexual que circunscrevem a sexualidade às "disfunçôes", mas também de convencer homens e mulheres idosos que a vida sexual não se extingue na velhice e que, se sua frequência diminui, o envelhecimento permite uma intensificação do prazer: o corpo masculino repleto de zonas erógenas a serem desenvolvidas e as mulheres liberando-se das amarras da moralidade vigente que as impede de usufruir plenamente desta dimensão da vida.

Os idosos pesquisados revelam que não é parte de seus horizontes a concreção de um momento em que se dará, como propõem os especialistas citados, "a erotização plena de toda a epiderme", em que "paixão e volúpia são substituídos por deleites mais refinados"; em que formas amorosas serão reinventadas, "em que os contatos físicos, como o olhar, o toque, a voz, passarão a erogenizar o corpo" e que, finalmente, ocorrerá uma síntese entre o desejo erótico e o amor terno. Se os homens manifestaram interesse em manter a vida sexual, essa manutenção está estreitamente relacionada com os imperativos da masculinidade. Redimensionar a sexualidade, tal como propõe a gerontologia, não faz eco num contexto em que os valores tradicionais de masculinidade e a resistência aos estereótipos da velhice - como um momento de perda de lucidez, de autocontrole e da vida sexual - organizam as práticas cotidianas dos idosos nos shopping centers, nas praças e nas associações de aposentados.

No que diz respeito às mulheres nos programas para a "terceira idade", nos bailes e nos esportes de praia, as etnografias mostram que uma experiência de envelhecimento bem-sucedida é independente de uma vida sexual gratificante. Elas se apressam em dizer que sabem, porque são lúcidas, que o corpo envelhecido não pode ser objeto de desejo. Ter vida sexual na velhice é, para elas, um desejo dos homens, dos "velhos bobos" que não percebem que apenas o dinheiro pode atrair as mulheres jovens que eles conquistam. Em sua visão, só as mulheres que já perderam a razão poderiam pretender ter uma vida sexual ativa. Os homens ainda teriam a chance de se relacionar com mulheres jovens, por- que, segundo elas, o dinheiro e poder erotizam o corpo masculino.

Essas diferenças de gênero na velhice se podem notar também em abordagens quantitativas sobre a sexualidade. Numa pesquisa do Datafolha, publicada em novembro de 2008, realizada com 1238 entrevistados, com 60 anos ou mais, em diferentes cidades do Brasil, 78\% dos homens declararam ter uma vida sexual normal e um quarto deles afirmou ter relações sexuais uma vez por semana. Nessa mesma pesquisa, apenas $24 \%$ das mulheres entrevistadas afirmaram ainda ter relações sexuais.

Em suma, os velhos apresentados nas etnografias não parecem interessados nos esforços da gerontologia e da sexologia de alargar as potencialidades da sexualidade humana e sequer mencionam a desgenitalização do corpo ou a inversão dos scripts masculinos e femininos anunciada por essas disciplinas como um ganho que a experiência de envelhecimento traz.

\section{Velhice e o erotismo politicamente correto: consideraçóes finais}

E a libido vai bem? Muitas mulheres hesitam em levar a questão para o consultório ginecológico, mas falta de desejo pode sinalizar problemas hormonais ou disfunção do ovário, além de ser efeito colateral de alguns anticoncepcionais. Boa Forma, 26 (3), fev. 2011, p. 60.

Explorar os limites da erotização da velhice foi o objetivo central deste artigo. Apresentamos os argumentos tecidos por gerontólogos e outros especialistas empenhados em demonstrar que a sexualidade não se esgota na velhice, mas, pelo contrário, é nesse o momento que ela poderia ser vivida em sua plenitude e experimentada de maneira igualitária entre os parceiros, especificamente quando o discurso competente propóe um cruzamento dos atributos de gênero comumente associados ao masculino e ao feminino. ${ }^{13}$

No entanto, é surpreendente constatar que não se coloque em pauta uma reflexão sobre a beleza do corpo envelhecido ou sobre a possibilidade dos velhos serem atraentes sexualmente. Não obstante todo o esforço de desconstrução de significados 
sociais em torno do envelhecimento e da sexualidade empreendido pela gerontologia e demais profissionais interessados na promoção destes temas, não consta de suas pretensões nenhuma intenção de promover, do ponto de vista estético, os corpos envelhecidos.

A problematização da sexualidade na velhice instaura uma nova dimensão na configuração do debate dos especialistas sobre o envelhecimento bem-sucedido. O conteúdo de suas argumentações e o desenho das tecnologias empregadas para sustentar a viabilidade de uma erotização da velhice estão diretamente condicionados a duas propostas da Organização Mundial de Saúde que são replicadas de maneira capilar em políticas e programas em diferentes partes do mundo: o modelo de envelhecimento ativo e o de saúde sexual. $\mathrm{Na}$ orientação dada por tais modelos, a sexualidade na velhice se define prioritariamente como um recurso para o bem-estar subjetivo. A experimentação do prazer proposta aos mais velhos está fortemente subordinada à gestão individual do envelhecimento segundo as noções contemporâneas de "qualidade de vida" e "vida saudável", com seus preceitos e critérios.

A operação de tratar a sexualidade em termos de seus pretensos benefícios para a saúde e o bem-estar vem progressivamente se popularizando e integra uma diversidade de discursos dirigidos à promoção da saúde. Como mostra a epígrafe destas considerações finais, extraída de uma revista voltada para o público feminino, possíveis causas orgânicas são cogitadas para explicar determinados comportamentos sexuais e remete-se à clínica médica para sua solução. É certo que a problematização em torno da libido e a tentativa de reificar as variações sexuais como disfunções não expressa exatamente o ponto de vista dos especialistas sobre velhice. Como dissemos, a medicina sexual parece ser o saber sobre a sexualidade que possui menor afinidade com o discurso gerontológico. Mesmo assim, o forte apelo à saúde constitui-se um recurso imprescindível para o processo mais amplo de erotização da velhice aqui debatido.

Essa associação da vida sexual com a saúde permite, por um lado, separar a gerontologia e a sexologia das práticas tidas como charlatanistas, que, como mostraram Marshall e Katz, caracterizavam o comércio de produtos voltados para estimular ou restaurar as funções sexuais perdidas e que se chocavam com a convenção dos especialistas que, até as primeiras décadas do século XX, estabeleciam que $\mathrm{o}$ vigor sexual era biologicamente determinado e que a aceitação do seu declínio era a condição para envelhecer bem. Por outro lado, a preocupação com a saúde - que permite dissociar o sexo de práticas exclusivamente hedonistas e garantir respeitabilidade ao que antes era tido como puro comércio de afrodisíacos - parece envolver um processo de apagamento da relação do erotismo com a beleza, dissociação essa que a proposta de instauração de uma relação nova e mais gratificante com a sexualidade tende a reforçar. É o erotismo politicamente correto que parece permitir que a beleza e a atração física possam ser colocadas num segundo plano na agenda dos entusiastas da sexualidade na velhice.

Com a expressão "erotismo politicamente correto”, Maria Filomena Gregori (2004) dá conta das novas faces do erotismo protagonizado por atores ligados à defesa das minorias sexuais e que tem como uma de suas implicações mais imediatas o deslocamento do sentido de clandestinidade do erotismo para um significado cada vez mais associado ao cuidado saudável do corpo e para o fortalecimento do self e da autoestima. Segundo sua argumentação, o que se ganha com o erotismo politicamente correto seria uma ampliação das possibilidades de escolhas e práticas sexuais. No entanto, observa que o erotismo e a pornografia perdem a conotação de obscenidade. Passam a associar-se a uma possibilidade válida entre as práticas sexuais, porém sua validade estaria conferida em função de sua capacidade de fortalecer e fazer bem ao sujeito. $\mathrm{O}$ uso que aqui fazemos desta noção aponta para uma ampliação de sua influência, reverberando entre os especialistas e sendo também replicado por eles.

O que se procurou mostrar nesse artigo é como essa nova face do erotismo afeta a gerontologia e a geriatria. É parte deste erotismo politicamente correto voltado para o envelhecimento questionar atributos tradicionais de gênero - questionamento que, como vimos, encontra na velhice um terreno propício e se expressa na prescrição da desgenitalização da sexualidade e na inversão dos scripts 
masculinos e femininos nas relações amorosas. A dimensão ética parece assim prescindir de qualquer esforço de estetização do corpo envelhecido, quando a preocupação central é a saúde.

Os padrões estabelecidos pela gerontologia, como procuramos mostrar, podem ser irreais para largos segmentos da população mais velha. Ficaram evidentes, com os poucos exemplos etnográficos trazidos, as dificuldades da gerontologia em promover a erotização da velhice. Os idosos abordados nas pesquisas antropológicas mencionadas revelam que não é parte de seus horizontes a concreção de um momento em que se dará "a erotização plena de toda a epiderme".

É preciso, no entanto, avaliar o significado do impacto do erotismo politicamente correto sobre as novas gerações de idosos, bem como o convite que está sendo feito para os babyboomers que estão envelhecendo num país que tem sido pensado como promotor do culto da beleza, da juventude e da sexualidade e num mundo em que a qualidade de vida e a felicidade estão estritamente relacionadas com uma vida sexual gratificante.

\section{Notas}

1 A gerontologia é a ciência que estuda o envelhecimento. A geriatria é o ramo da medicina voltado para a velhice. Nesse artigo estamos usando o termo gerontólogos e gerontologia em sentido amplo, compreendendo os profissionais e pesquisadores de várias especialidades empenhados em propor atitudes, estilos de vida e formas de consumo de bens e serviços para um envelhecimento bem-sucedido.

2 A questão estava inspirada no relatório apresentado por Mariza Corrêa no projeto temático "Gênero e corporalidade", Fapesp, 2004-2008.

3 Sobre o campo da gerontologia, ver Debert (1999) e Lopes (2000).

4 Ver críticas a essas teorias em Maddox (1969).

5 As citações a seguir servem como exemplos: "Estudos indicam que o sexo em pessoas de idade parece improvável ou desagradável, para velhos e jovens, incluindo as pessoas que trabalham com os velhos Essas conclusões levam, no entanto, a uma confusão, dada a tendência de as pessoas responderem sobre o tema de formas tidas como socialmente aceitáveis. Ou seja, os participantes podem ter respondido de forma a reproduzir mitos culturais e não com base em suas crenças pessoais, mas porque a sociedade apoia e sanciona esses mitos" (Ludeman, 1981, p. 204). "[A] sociedade conspira para negar a satisfação sexual dos idosos de várias maneiras [...]. Atitudes culturais que reverenciam a reprodução e a aparência jovial podem contribuir para a expectativa de que as pessoas idosas são, ou deveriam ser, assexuadas. Atitudes negativas em relação ao sexo apreendidas na juventude podem prejudicar gravemente a capacidade de desfrutar do sexo na vida adulta” (Deacon et al., 1995, p. 497) [Tradução livre].

6 Ou em uma versão mais atualizada: "Os adultos mais velhos que têm parceiros fixos ou que são sexualmente ativos tendem, mais do que os sexualmente inativos, a classificar o sexo como sendo "muito importante" ou como uma prioridade "extremamente" importante em suas vidas. Quando a atividade sexual é menos frequente, muitos idosos acreditam que isto é 'uma parte normal do envelhecimento' ou 'normal em um relacionamento de longa duração', permitindo, assim, que as pessoas mais velhas possam lidar com as mudanças na sua vida sexual" (Wylie et al., 2011, p. 16) [Tradução livre].

7 As inter-relações discursivas entre sexo, saúde e bem-estar devem ser consideradas no conjunto de processos que concorrem para a transformação dos modos de tratar atualmente a sexualidade dos velhos. A noção de saúde sexual, cunhada em meados dos anos de 1970 pela OMS é fundamental para entender historicamente a proposição da sexualidade como uma questão de saúde pública. Em sua análise sobre o conceito, Giami (2002) sustenta que a regulação da sexualidade em termos de saúde pública depende diretamente do contexto nacional, político e cultural. $\mathrm{O}$ autor adverte que não há um consenso sobre sua definição; os usos dessa noção podem abranger tanto o nível da responsabilidade individual, como a organização de serviços de saúde sexual apropriados. A saúde sexual pode ser entendida não só como um estado ideal de bem-estar, mas também como a redução de efeitos negativos da atividade sexual.

8 Cf. a análise excelente empreendida pelo autor da sexualidade na literatura antropológica em Piscitelli, Gregori e Carrara (2004).

9 Sobre o tema, ver Alves (1999), Alves (2004), Barros (1998), Brigeiro (2000), Britto da Motta (1997) Cabral (1997), Eckert (1998), Motta (1998), Peixoto (2000), Santos e Rifiotis (2004), Scott, (2006), Simões (1998, 2000, 2004a e b). No Brasil, pesquisas 
de cunho qualitativo também criticam a tendência das análises de exagerarem a perspectiva da miséria na velhice. Trabalhos como o de Myriam Moraes Lins de Barros (1987), de Clarice Peixoto (1995) e os de Guita Debert (1999), com indivíduos de mais idade de setores médios, sugeriam que a representação que os idosos faziam de sua situação não era tão trágica como aquela apresentada pelo discurso gerontológico. Nesses trabalhos, entretanto, a tendência era manter a perspectiva da miséria do envelhecimento através do uso de dois recursos principais. Considerando, de um lado, que os setores médios, dadas as diferenças de renda no país, representavam uma exceção no quadro trágico da velhice dos mais pobres, como destino da grande maioria dos velhos brasileiros; e, de outro, que a própria escolha dos grupos estudados estava dirigida para setores muito especiais e numericamente pouco representativos, não se podendo generalizar os resultados das pesquisas de cunho qualitativo, nem mesmo para os setores médios.

10 Sobre o movimento dos aposentados, ver Simões (2000).

11 Ver também Brigeiro (2002).

12 É também um interessante exemplo etnográfico sobre as hierarquias de idade em universos de sociabilidade homoerótica o trabalho de Henning (2008).

13 É importante afirmar que está ausente da bibliografia especializada que revisamos qualquer preocupação com as assimetrias nas relações de gênero, ainda que eventualmente os especialistas especulem como determinadas normas associadas ao masculino e ao feminino podem representar um obstáculo para a livre expressão e satisfação sexual de homens e mulheres. A velhice, em vez de esgotar a expressão sexual, inauguraria uma nova fase para sua experimentação. A necessidade de um novo posicionamento individual diante da sexualidade é prescrita pelos especialistas e complementada por uma proposta de revisão subjetiva sobre as amarras de gênero, mas isto sem questionar as assimetrias relacionais, ficando a reflexão restrita ao plano individual.

\section{BIBLIOGRAFIA}

ALVES, Andréa Moraes. (2004), A dama e o cavalheiro: um estudo antropológico sobre envelhecimento, gênero e sociabilidade. Rio de Janeiro, FGV.
ALVES, Marcelo. (1999), “A gestão da experiência de envelhecer em um programa para a terceira idade: a Unati/Uerj”. Textos Envelhecimento, 2 (2): 23-63.

BAJOS, Natalie \& BOZON, Michel. (1999), "La sexualité à l'épreuve de la medicalisation: le Viagra". Actes de la Recherche en Sciences Sociales (Sur la Sexualité), 128: 34-37.

BARROS, Myrian Moraes Lins de. (1987), Autoridade e afeto: avós, filhos e netos na família brasileira. Rio de Janeiro, Zahar.

(1998), "Testemunho de vida: um estudo antropológico de mulheres na velhice”, in _org.), Velhice ou terceira idade? Rio de Janeiro, FGV, pp. 113-169.

BÉJIN, André. (1987), “O poder dos sexólogos e a democracia sexual”, in Phillipe Ariés e André Béjin (orgs.), Sexualidades ocidentais. 3. ed. São Paulo, Brasiliense, pp. 236-254.

BOZON, Michel. (2004), Sociologia da sexualidade. Rio de Janeiro, FGV.

BRIGEIRO, Mauro. (2000), Rir ou chorar? Envelhecimento, sexualidade e sociabilidade masculina. Rio de Janeiro, dissertação de mestrado em Saúde Coletiva, Instituto de Medicina Social, Universidade do Estado do Rio de Janeiro. (2002), "Envelhecimento bem-sucedido e sexualidade: relativizando uma problemática", in, Regina Barbosa et al. (orgs.), Interfaces: gênero, sexualidade e saúde reprodutiva, Campinas, SP, Editora da Unicamp, pp. 171-206.

BRIGEIRO, Mauro \& MAKSUD, Ivia. (2009), "Aparição do Viagra na cena pública brasileira: discursos sobre corpo, gênero e sexualidade na mídia”. Estudos Feministas, 17 (1): 71-88, jan.-abr., Florianópolis.

BRITTO DA MOTTA, Alda. (1997), "Palavras e convivência: idosos hoje”. Estudos Feministas, 5 (1): 129-135, Rio de Janeiro.

CABRAL, Benedita Lima. (1997), "A vida começa todo dia”. Estudos Feministas, 5 (1): 159-168, Rio de Janeiro.

COHEN, Lawrence. (1994), “Old age: cultural and critical perspectives". Annual Review of Anthropology, 23: 137-158.

CORREAA, Mariza. (2004), "Gênero e corporalidade”. Fapesp, projeto temático, 2004-2008. 
CUMMING, Elaine \& HENRY, Willian. (1961), Growing old. Nova York, Basic Books.

CAVAN, Ruth. (1965), "Family tensions between the old and middle aged", in C. Vedder (org.), The problem of the middle aged. Springfield, Tomas Publishing.

ECKERT, Cornelia. (1998), "A vida em um outro lugar", in Myrian Moraes Lins de Barros (org.), Velhice ou terceira idade? Rio de Janeiro, FGV.

DEACON, Susan et al. (1995), "Sexuality and older people: revisiting the assumptions". Educational Gerontology, 21: 497-513.

DEBERT, Guita. (1999), A reinvenção da velhice. São Paulo, Edusp.

GREGORI, Maria Filomena. (2004), "Prazer e perigo: notas sobre feminismo, sex shops e S/M", in Adriana Piscitelli, Maria Filomena Gregori e Sérgio Carrara, Sexualidades e saberes, convençôes e fronteiras, Rio de Janeiro, Garamond, pp. 235-257.

DUARTE, Luís Fernando Dias. (2004), “A sexualidade nas ciências sociais: leitura crítica das convenções", in Adriana Piscitelli, Maria Filomena Gregori e Sérgio Carrara, Sexualidades e saberes, convençôes e fronteiras, Rio de Janeiro, Garamond, pp. 39-81.

FERRIGNO, José Carlos. (1988), "A sexualidade dos mais velhos". Intercâmbio, 31 (1): 5-16.

FUCS, Gilda. (1992), Homens e mulheres: encontros e desencontros. Rio de Janeiro, Rosa dos Tempos.

GIAMI, Alain. (1998), "La medicalisation de la sexualité: aspects sociologiques et historiques". Andrologie, 8 (3): 383-390.

. (2002), "Sexual helth: the emergence, development, and diversity of a concept". Annul Review of Sex Research, 13: 1-35.

HENNING, Carlos Eduardo. (2008), As diferenças na diferença: hierarquia e intercessão de geração, gênero, classe, raça e corporalidade em bares e boates GLS de Florianópolis. Florianópollis, dissertação de Mestrado, Universidade Federal de Santa Catarina.

KATZ, Stephen \& MARSHALL, Barabara. (2003), "New sex for old: lifestyle, consumerism, and the ethics of aging well". Journal of Aging Studies, 17 (1): 3-16.
KERNBERG, Otto F. (2001), "Love relations in later years", in R. Steines \& J. Johns (eds.), Within time \& beyond time: a festschrift for Pearl King, Londres, Karnak Books.

LOPES, Andrea. (2000), Os desafios da gerontologia no Brasil. Campinas, SP, Alínea.

LUDEMAN, Kate. (1981), "The sexuality of the older person: review of the literature". The Gerontologist, 21 (2): 203-208.

MADDOX, George. (1969), "Growing old: getting beyond the stereotypes", in Rosamonde Boyd e Charles Oakes (orgs.), Foundations of practical gerontology, Columbia, University of South Caroline Press.

MAIA, Mônica \& LOPES, Gerson. (1994), Sexualidade e envelhecimento. São Paulo, Saraiva.

MOTTA, Flávia de Mattos. (1998), Velha é a vovozinha: identidade feminina na velhice. Santa Cruz do Sul, Edunisc.

PEIXOTO, Clarice Ehler. (1995), "A sociabilidade dos idosos cariocas e parisienses: a busca de estratégias para preencher o vazio da inatividade". Revista Brasileira de Ciências Sociais, 27: 138-149.

(1997), "De volta às aulas ou como ser estudante aos 60 anos", in Renato Peixoto Veras (org.), Terceira idade: desafios para o terceiro milênio, Rio de Janeiro, Relume-Dumará, pp. 41-74. . (2000). ENVELHECIMENTO E IMAGENS: ENTRE PARIS E RIO DE JANEIRO. SÃO PAULO, Annablume.

PISCITELLI, Adriana; GREGORI, Maria Filomena \& CARRARA, Sérgio. Sexualidades e saberes, convençôes e fronteiras. Rio de Janeiro, Garamond.

RISMAN, Arnaldo. (1995). "Atividade sexual na velhice" in Renato Peixoto Veras (org.), Terceira idade: desafios para o terceiro milênio, Rio de Janeiro, Relume-Dumará.

RUSSO, Jane et al. (2011), Sexualidade, ciência e profissão no Brasil. Rio de Janeiro, Cepesc.

SÁ, J. L. M. (1991), A Universidade da Terceira Idade na Puccamp: proposta e ação inicial. Campinas, Puccampinas.

SANTOS, Silvia Maria Azevedo dos \& RIFIOTIS, Theophilos. (2004), "Cuidadores familiares de 
idosos dementados: uma reflexão sobre o cuidado e o papel dos conflitos na dinâmica da família cuidadora", in Meire Cachione, Olga von Simpson e Anita Neri (orgs.), As múltiplas faces da velhice, Campinas, SP, Alínea, pp. 141-164.

SANTOS, Sueli Souza dos. (2003), Sexualidade e amor na velhice. Porto Alegre, Sulina.

SCOTT, Perry. (2006), "Gerações, comunidades e o programa Saúde da Família: reprodução, disciplina e a simplificação administrativa”, in Myrian Moraes Lins de Barros (org.), Família e geraçôes, Rio de Janeiro, FGV, pp. 107-130.

SILVERMAN, P. (1987), "Introduction: the life course perspective", in (org.), The elderly as modern pioneers, Indianapolis, Indiana University Press

SIMÕES, Júlio de Assis. (1998), "A maior categoria do país: o aposentado como ator político", in Myrian Moraes Lins de Barros (org.), Velhice ou terceira idade? Rio de Janeiro, FGV.

. (2000), Entre o lobby e as ruas: movimento de aposentados e politização da aposentadoria. Campinas, tese de doutorado, Unicamp. . (2004A), "Provedores e militantes: imagens de homens aposentados na família e na vida pública", in C. Peixoto (org.), Família e envelhecimento. Rio de Janeiro, FGV, pp. 2556.

. (2004B), "Homossexualidade masculina e curso da vida: pensando idades e identidades sexuais", in Adriana Piscitelli, Maria Filomena Gregori e Sérgio Carrara, Sexualidades e saberes, convençôes e fronteiras, Rio de Janeiro, Garamond, pp. 415-447.

STUCCHI, Deborah. (1998), "O curso da vida no contexto da lógica empresarial: juventude maturidade e produtividade na definição da pré-aposentadoria” in Myrian Moraes Lins de Barros (org.), Velhice ou terceira idade? Rio de Janeiro, FGV.

TORNSTAM, L. (1992), "The quo vadis of gerontology: on the scientific paradigm of gerontology". The Gerontologist, 32 (3): 318-326.

WYLIE ET AL. (2011), "Challenges of the sexual health $(\mathrm{SH})$ of the elderly in Europe". Entre Nous: The European Magazine for Sexual and Reproductive Health, 72: 16-17. 


\section{FRONTEIRAS DE GÊNERO E A SEXUALIDADE NA VELHICE}

\section{Guita Debert e Mauro Brigeiro}

Palavras-chave: Velhice; Sexualidade; Gerontologia; Gênero.

O objetivo deste artigo é descrever as características do processo que denominaremos "erotização da velhice", discutindo alguns de seus possíveis significados no marco das formas contemporâneas de gestão do envelhecimento e analisando as diferenciações de gênero que aí se operam, bem como certas fusões. Tomamos como base para nossa reflexão algumas publicaçóes nacionais e internacionais sobre sexualidade na velhice, bem como dados etnográficos extraídos de pesquisas brasileiras realizadas em espaços de sociabilidade de velhos. Estes dados exemplificam o ponto de vista de mulheres participantes de grupos de terceira idade e de homens integrantes de associações de aposentados ou de redes de sociabilidade masculina a respeito do tema e servem de excelente contraponto para pensar os parâmetros estabelecidos pelos especialistas que se empenham em incluir a velhice no curso da vida sexual, propondo que o declínio da frequência de atividade sexual com o avanço da idade é compensado por uma intensidade ampliada do prazer.

\section{BOUNDARIES OF GENDER AND SEXUALITY IN OLD AGE}

\section{Guita Debert and Mauro Brigeiro}

Keywords: Old Age; Sexuality; Gender; Gerontology.

Drawing on the interplay of gender, ageing, and sexuality, the aim of this essay is twofold. On the one hand, to describe what we are calling the process of "eroticization of old age" and to explore through content analysis of the gerontological discourse how gender differences are dissolved in the attempt to demonstrate that the decrease in sexual activity in old age is replaced by a unique and intense sexual pleasure. On the other hand, to analyze, based on ethnographical accounts on elderly groups and associations, as senior citizen clubs and retirees organizations, the way in which these discourses on the ageing body and sexuality are differently perceived and evaluated by older men and women. The essay is therefore an attempt to present the difficulties faced by contemporary gerontology in order to promote eroticism in old age as well as an inseparable relationship between sexual pleasure and health.

\section{FRONTIẼRES DE GENRE ET SEXUALITÉ DANS LA VIEILLESSE}

\section{Guita Debert et Mauro Brigeiro}

Mots-clés: Vieillesse; Sexualité; Gérontologie; Genre.

L'objectif de cet article est de décrire les caractéristiques du processus que nous dénommons "érotisation de la vieillesse». Nous aborderons certaines de ses possibles significations dans le cadre des formes contemporaines de gestion du vieillissement et analyserons les différences de genre qui y ont lieu ainsi que certaines fusions. Notre réflexion s'est fondée sur des publications nationales et internationales à propos de la sexualité dans la vieillesse ainsi que sur des données ethnographiques extraites de recherches brésiliennes réalisées dans des maisons de retraite. Ces données représentent l'exemple du point de vue des femmes issues de groupes du troisième âge et d'hommes qui font partie d'associations de retraités ou de réseaux de sociabilité masculine sur ce thème. Ils servent d'excellent contrepoint pour analyser les paramètres établis par les spécialistes qui s'efforcent à inclure la vieillesse dans le cours de la vie sexuelle. Ces spécialistes suggèrent que la diminution de la fréquence de l'activité sexuelle due à l'avance de l'âge est compensée par un plaisir d'intensité accrue. 